Universidad de Lima

Facultad de Derecho

Carrera de Derecho

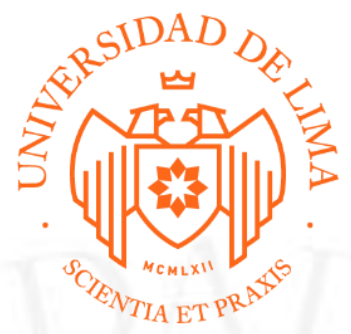

\title{
CIVIL: "RESPONSABILIDAD CIVIL Y PERJUICIOS" Y ADMINISTRATIVO: "PROTECCIÓN AL CONSUMIDOR"
}

Trabajo de suficiencia profesional para optar el Título Profesional de Abogada

\author{
Adriana Marin Rozas
}

Código 20131987

$$
\text { Lima - Perú }
$$

Septiembre de 2019 


\section{CIVIL: "RESPONSABILIDAD CIVIL Y PERJUICIOS" \\ Materia: Responsabilidad civil incumplimiento obligacional \\ $\mathrm{N}^{\mathrm{o}}$ de Expediente: DE - ARBIT0085}

\section{RESUMEN}

El presente caso es un arbitraje en el cual la empresa A. A. A demanda a B. B. B. el pago de daños y perjuicios por el incumplimiento de la obligación referida a la entrega de páprika en los meses de enero y febrero de 2007.

\section{ADMINISTRATIVO: "PROTECCIÓN AL CONSUMIDOR"}

Materia: Protección al consumidor

$\mathrm{N}^{\mathrm{o}}$ de Expediente: DE-INDECO 0441

\section{RESUMEN}

El presente caso es acerca de una denuncia presentada por el señor C. C. C. ante el Instituto Nacional de Defensa de la Competencia y de la Protección de la Propiedad Intelectual en contra el D. D. D. Los hechos materia de infracción son (i) una transacción en ventanilla no reconocida por S/ 30000.00 y (ii) infringir el deber de información. 